\title{
Antiangiogenic activity of a concentrated effective microorganism fermentation extract
}

\author{
CHUNG HIN CHUI ${ }^{1,2 *}$, ROBERTO GAMBARI ${ }^{3 *}$, FUNG YI LAU ${ }^{2}$, \\ DESMOND KWOK PO HAU ${ }^{4}$, RAYMOND SIU MING WONG ${ }^{2}$, GREGORY YIN MING CHENG ${ }^{2}$, \\ STANTON HON LUNG KOK ${ }^{1}$, TERUO HIGA ${ }^{5}$, BIN KE ${ }^{6}$, ALBERT SUN CHI CHAN ${ }^{1}$, \\ DAVID WAN FUN FONG ${ }^{4}$ and JOHNNY CHEUK ON TANG ${ }^{1}$
}

\begin{abstract}
${ }^{1}$ Cancer Drug Development and Research Laboratory, Central Laboratory of the Institute of Molecular Technology for Drug Discovery and Synthesis, State Key Laboratory of Chinese Medicine and Molecular Pharmacology, Department of Applied Biology and Chemical Technology, The Hong Kong Polytechnic University; ${ }^{2}$ Department of Medicine and Therapeutics, Prince of Wales Hospital, The Chinese University of Hong Kong, Hong Kong, P.R. China; ${ }^{3}$ ER-GenTech, Department of Biochemistry and Molecular Biology, Section of Molecular Biology, University of Ferrara, Ferrara, Italy; ${ }^{4}$ Research and Development Division, School of Chinese Medicine, The Baptist University of Hong Kong, Hong Kong, P.R. China; ${ }^{5}$ Faculty of Agriculture, University of the Ryukyus, Ryukyus; ${ }^{6} \mathrm{EM}$ Research Organization, Okinawa, Japan
\end{abstract}

Received March 29, 2006; Accepted July 11, 2006

\begin{abstract}
We have previously demonstrated the possible growth inhibitory activity of both first generation of the effective microorganism fermentation extract (EM-X) as well as the second generation (EM-X2) on cancer cell lines in vitro. The possible anti-angiogenic potential of EM-X has not been reported. Herein we show that using the concentrated EM-X, the growth of human umbilical cord endothelial cells (HUCE) was significantly inhibited in vitro. Enzyme linked immunosorbent assay suggested that the concentrated EM-X is able to reduce the level of vascular endothelial growth factor (VEGF) from Hep3B hepatocellular carcinoma (HCC) cells. The conditioned culture medium obtained from the concentrated EM-X incubated Hep3B HCC cells possessed significant antiproliferative effect on the HUCE cells. Moreover, in vivo chick chorioallantoic membrane assay further demon-strated that the concentrated EM-X is able to greatly inhibit the basic fibroblast growth factor induced angiogenesis from chick
\end{abstract}

Correspondence to: Dr Johnny Cheuk On Tang, Department of Applied Biology and Chemical Technology, The Hong Kong Polytechnic University, Hung Hom, Kowloon, Hong Kong, P.R. China

E-mail: bccotang@inet.polyu.edu.hk

${ }^{*}$ Contributed equally

Key words: chick chorioallantoic membrane, effective microorganism fermentation extract, human umbilical cord endothelial cell embryo experiment. We speculate that the anti-cancer potential of this concentrated EM-X involved growth inhibition on cancer cell and antiangiogenic effect on HUCE cells.

\section{Introduction}

Tumour growth is closely associated with the development of new blood vessels for the supply of nutrients to cancer cells. Without neovascular formation, tumour volume does not enlarge and is unable to undergo metastasis. Accordingly, the identification and development of both cytotoxic and antiangiogenic agents are of great interest in basic research as well as in applied clinical studies aimed at the onset of novel anti-cancer therapeutic approaches (1-3).

The effective microorganism fermented extract (EM-X, the first generation) is a refreshment drink commonly found in East Asia, especially in Japan. EM-X is produced by fermentation of papaya, rice bran and seaweed extract using effective micro-organisms, containing more than one hundred bacterial strains, including photosynthetic bacteria, lactic acid bacteria, and yeast. EM-X is rich in antioxidants including $\alpha$ tocopherol, flavonoids, lycopene, minerals, saponin and ubiquinone. We have demonstrated the growth inhibitory activity of the second generation of EM-X (EM-X2) on breast cancer MDA-MB231 and chronic myelogenous leukaemia K-562 cell lines. Elevation of superoxide dismutase activity in extracts isolated from cancer cells treated with EM-X2 was observed (4). Furthermore, the possible anti-cancer activity of EM-X in its concentrated form was reported (5). We also demonstrated that the concentrated form of EM-X possesses antiproliferative ability together with induction of apoptosis on human cancer cell lines, including Hep3B hepatocellular carcinoma (HCC) and KG1a acute myelogenous leukaemia 


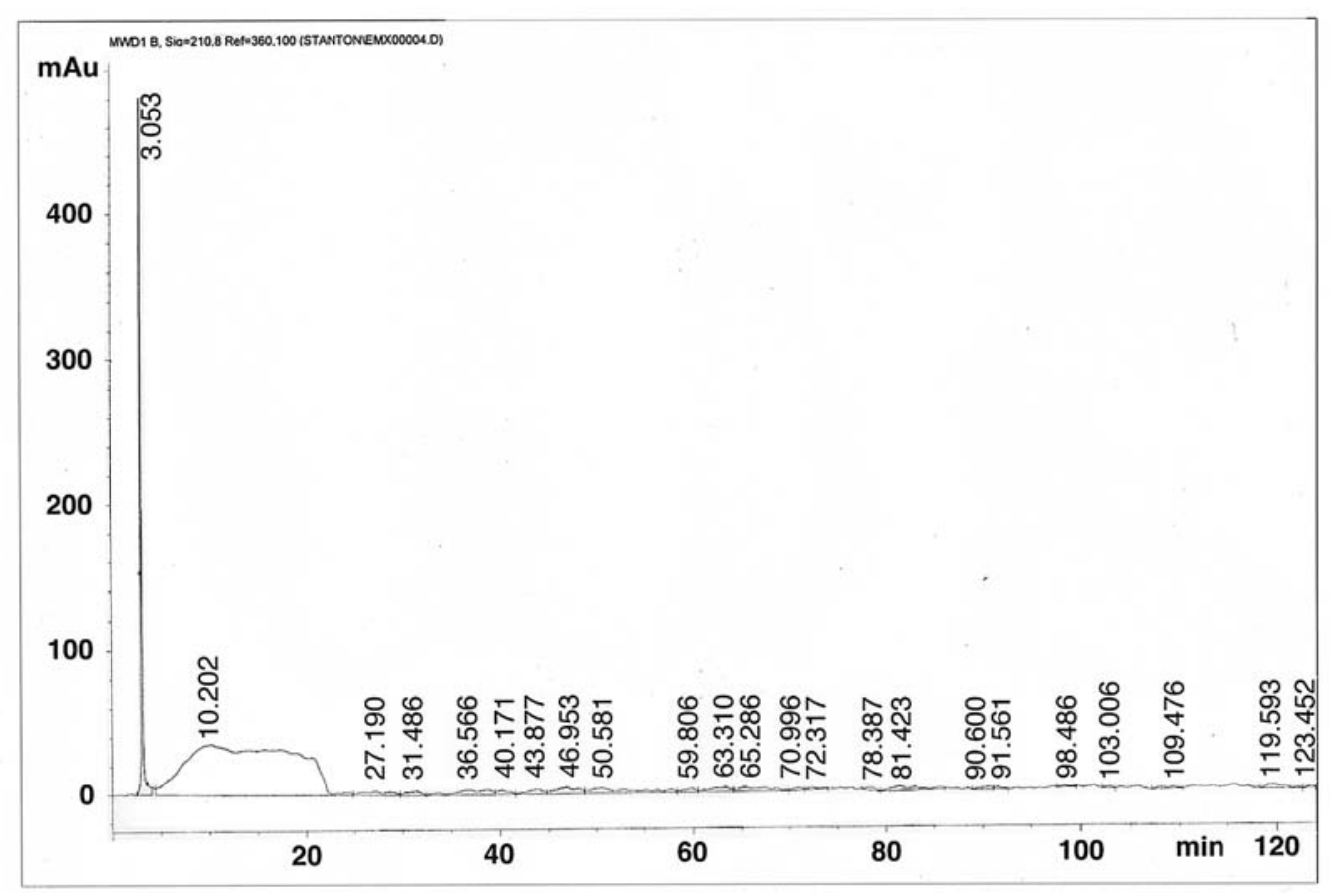

Figure 1. High performance liquid chromatography characterization for the preparation of concentrated EM-X standard reference from its original fluid.

cell lines. However, its possible antiangiogenic effects were not investigated.

The major objective of the present study was to determine whether concentrated EM-X exhibits antiangiogenic properties. To this aim we first determined whether the concentrated EM-X is antiproliferative towards human umbilical cord endothelial cell (HUCE) in vitro. Second, we tested whether the concentrated EM-X could reduce the level of vascular endothelial growth factor (VEGF) from Hep3B HCC cells. Third, we determined whether the concentrated EM-X could reduce the blood vessel formation which was induced by the basic fibroblast growth factor (bFGF) in vivo using the chick chorioallantoic membrane assay (CAM).

\section{Materials and methods}

Preparation of concentrated EM-X. The original pale greenish fluid of EM-X was mixed with absolute ethanol. The mixture was then warmed in a round bottomed flask using a rotatory evaporator under a warm water bath. When all fluid was evaporated, the net weight of the dried extract was measured. The volume of fluid from each step was also recorded. The dried extract was then dissolved in sterile distilled water to a final concentration of $20 \mathrm{mg} / \mathrm{ml}$. The concentrated EM-X was further filtered by a $0.22-\mu \mathrm{m}$ filter. The filtrate was then stored in aliquots at $-20^{\circ} \mathrm{C}$ until use.

High performance liquid chromatography (HPLC) analysis of concentrated EM-X. Concentrated EM-X solution was subjected to HPLC analysis in order to obtain reference standard using a solvent system of methanol to water (1:1) and flow rate of $0.8 \mathrm{ml} / \mathrm{mim}$ in a Capcell column using the Agilent 1100 series HPLC machine.
Cell lines and cell culture. The cell lines employed in this study included the HCC origin Hep3B and the HUCE cells, obtained from the American Type of Culture Collection. They were maintained routinely in minimum essential medium (MEM) cell culture medium (JRH BioSciences) supplemented with 5\% fetal bovine serum (Hyclone) together with penicillin and streptomycin (Invitrogen). They were further kept in a 5\% carbon dioxide humidified incubator at $37^{\circ} \mathrm{C}$.

Antiproliferative assay. The 1-step ATP Lite luminescence kit purchased from Perkin Elmer was used to test the antiproliferative and cytotoxic activites of concentrated EM-X as reported (6). Briefly, different cells were seeded in a 96-well microtitre plate on the first day. On the second day, growth medium was refreshed and different concentrations of concentrated EM-X [starting from $10 \%$ (v/v) by volume ratio, thus effective concentration started from $2 \mathrm{mg} / \mathrm{ml}$ ] was added. In each case, $10 \%(\mathrm{v} / \mathrm{v})$ of sterilized water was used as control while for concentrated EM-X, it was serially diluted with sterile distilled water so that water would always contribute to $10 \%(\mathrm{v} / \mathrm{v})$ of final volume. After $48 \mathrm{~h}$, the resulting luminescence from water control and concentrated EM-Xtreated cells were measured using a Victor $^{2} \mathrm{~V}$ multilabel 1420 counter (Perkin Elmer) according to the instructions provided.

Morphological changes of EM-X-treated HUEC cells. HUCE cells were seeded in growth medium as mentioned before and then $2 \mathrm{mg} / \mathrm{ml}$ of concentrated EM-X was added. Any morphological changes after $48 \mathrm{~h}$ were observed under an inverted microscope (7). 


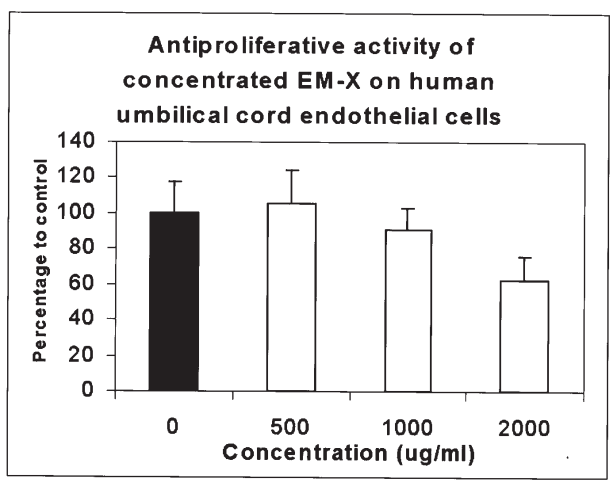

Figure 2. Growth inhibitory activity of concentrated EM-X on the human umbilical cord endothelial cell. Result are the mean \pm SD of one representative experiment. Triplicate tests were performed from each experiment. A total of three experiments were done and similar results obtained.
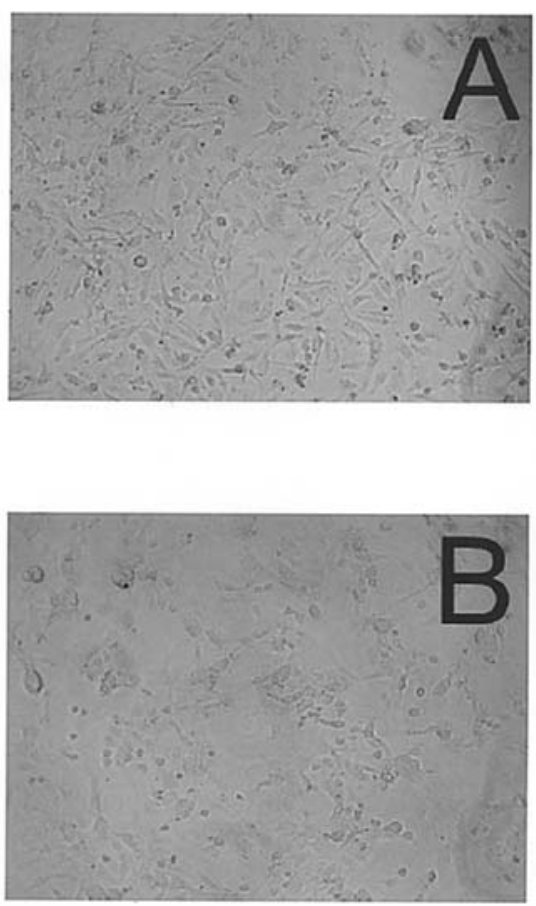

Figure 3. Morphological investigation of umbilical cord endothelial cells with or without incubation of concentrated EM-X $(2 \mathrm{mg} / \mathrm{ml})$ after $48 \mathrm{~h}$. (A) Vehicle control. (B) Treated with concentrated EM-X.

Quantification of VEGF level from concentrated EM-X incubated Hep3B HCC cells. After concentrated EM-X incubation at different dosages, in the conditioned serumfree medium, supernatants were prepared for VEGF level measurement, while Hep 3B cell pellets were prepared for total protein content standardization. VEGF concentrations were measured by using a quantitative sandwich enzyme linked immunosorbent assay technique (Oncogene). All the measurements were carried out according to the instructions provided. An ELISA microplate reader measured optical densities at $450 \mathrm{~nm}$ and correction of the reading measured at $540 \mathrm{~nm}$. Protein levels were measured by standard the Bradford method (Bio-Rad) at $595 \mathrm{~nm}$ using the bovine serum albumin as the standard calibration (8). Results were expressed as pg of VEGF per $0.1 \mathrm{mg}$ of total cellular protein.

Preparation of conditioned medium from Hep3B HCC cells for the HUCE cell culture. Hep3B cells were seeded in culture disc with growth medium on the first day. On the second day, growth medium was removed and the attached HCC cells were washed with calcium ion and magnesium ion-free PBS 3 times. Afterwards, serum-free medium and concentrated EM-X $(2 \mathrm{mg} / \mathrm{ml})$ were added accordingly. HCC cells were further incubated for $48 \mathrm{~h}$. Lastly, the conditioned medium was collected and centrifuged in order to remove the cell debris. The conditioned medium was stored at $-70^{\circ} \mathrm{C}$ until use.

In vivo CAM assay. On day zero, fertilized eggs were incubated at $37^{\circ} \mathrm{C}$ humidified incubator. On day 3 , the shell was cracked in a sterilized container and $\sim 3 \mathrm{ml}$ of albumin was removed. They were further incubated at $37^{\circ} \mathrm{C}$. On day 7 , a sterilize $3 \mathrm{MM}$ filter paper containing $40 \mathrm{ng}$ of bFGF (R \& D) or $40 \mathrm{ng}$ of bFGF together with $100 \mu \mathrm{g}$ of concentrated EM-X were placed on the membrane. A control was done using phosphatebuffered saline. Four eggs were used for each group. Eggs were further incubated at $37^{\circ} \mathrm{C}$ for 4 days. Afterwards, membrane was fixed with formalin and new blood vessel formation was inspected under a dissection microscope. Representative photomicrographs from each group were recorded (8).

\section{Results}

HPLC analysis of the concentrated EM-X. Fig. 1 shows the HPLC pattern of the concentrated EM-X performed at $210 \mathrm{~nm}$. It was used as a fingerprinting reference standard for further concentrated EM-X characterization during preparation.

Concentrated EM-X is able to inhibit the growth of human cord endothelial (HUCE) cells. After incubating HUCE cells for $48 \mathrm{~h}$ with increasing amounts of concentrated EM-X, a dose- dependent antiproliferative effect was observed. As shown in Fig. 2, growth inhibition was detectable when EM$\mathrm{X}$ was used at $2 \mathrm{mg} / \mathrm{ml}$. However, no significant difference was found with respect to control untreated HUCE cells, when the concentrated EM-X levels were 0.5 and $1 \mathrm{mg} / \mathrm{ml}$.

Morphological investigation of HUCE cells after incubation with concentrated EM-X. After incubating HUCE cells with $2 \mathrm{mg} / \mathrm{ml}$ of concentrated EM-X for $48 \mathrm{~h}$, we investigated whether there was any morphological variations on the treated HUCE cells. Fig. 3B shows that there was only reduction in cell density when cells treated with concentrated EM-X were compared with control cells cultured with vehicle (Fig. 3A). The results obtained suggest that apoptosis is not induced by concentrated EM-X at this concentration and using the reported time schedule, since neither cell shrinkage nor cell rounding was found.

Concentrated EM-X reduced the level of VEGF from Hep3B $H C C$ cells. To see whether concentrated EM-X could affect the level of VEGF from Hep 3B HCC cells, we quantitated 

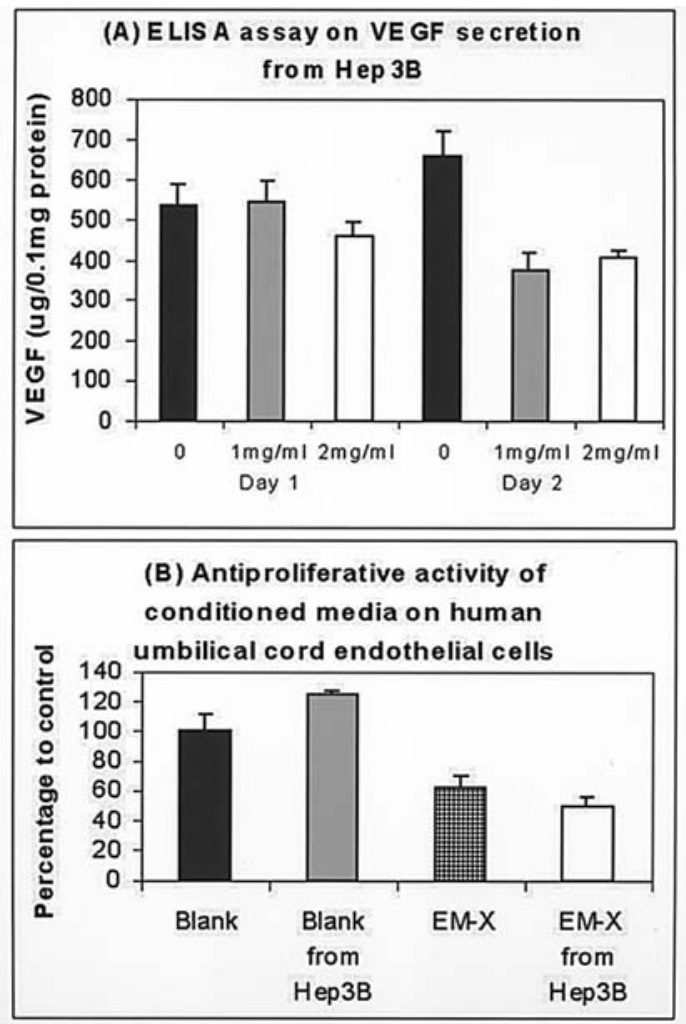

Figure 4. (A) Enzyme linked immunosorbent assay for the detection of vascular endothelial cell growth factor (VEGF) from human umbilical cord endothelial cells under the influence of concentrated EM-X after $24 \mathrm{~h}$ and $48 \mathrm{~h}$. Three independent experiments were performed and their mean \pm SD is shown. (B) Influence of the conditioned medium on the growth of human umbilical cord endothelial cells. Blank: medium with $10 \%$ water collected after $48 \mathrm{~h}$ of 'no cell' condition. Blank from Hep3B: medium with $10 \%$ water collected after $48 \mathrm{~h}$ of Hep3B incubation. EM-X: medium with $10 \%$ of $20 \mathrm{mg} / \mathrm{ml}$ EM-X collected after $48 \mathrm{~h}$ of 'no cell' condition. EM-X from Hep 3B: medium with $10 \%$ of $20 \mathrm{mg} / \mathrm{ml} \mathrm{EM-X} \mathrm{collected} \mathrm{after} 48 \mathrm{~h}$ of Hep3B incubation. Triplicate tests were performed for each experiment. A total of three experiments were done and similar results obtained.

the VEGF at two time points using an ELISA assay and normalizing the results obtained with the total protein content. After the first $24 \mathrm{~h}$ of incubation, concentrated EM-X at $2 \mathrm{mg}$ / $\mathrm{ml}$ reduces only slightly VEGF levels. However, after $48 \mathrm{~h}$ of incubation, concentrated EM-X at both $1 \mathrm{mg} / \mathrm{ml}$ and $2 \mathrm{mg} / \mathrm{ml}$ significantly reduced the VEGF level (Fig. 4A).

Conditioned culture medium from concentrated EM-Xtreated Hep $3 B$ cells inhibit the growth of HUCE cells. The conditioned medium from untreated Hep 3B HCC cells enhanced the growth of HUCE cells when compared with the HUCE cells cultured in blank medium. However, the conditioned medium derived from concentrated EM-X (2 mg/ ml)-treated Hep 3B HCC cells is able to greatly inhibit the growth of HUCE cells (Fig. 4B).

In vivo CAM assay. In vivo chorioallantoic membrane assay was performed to study the effect of concentrated EM-X on the angiogenicity induced by bFGF. The results obtained clearly demonstrate that concentrated EM-X used at $100 \mu \mathrm{g}$ is able to inhibit the angiogenic activity induced by $40 \mathrm{ng}$ of bFGF as new blood vessel formation was reduced when
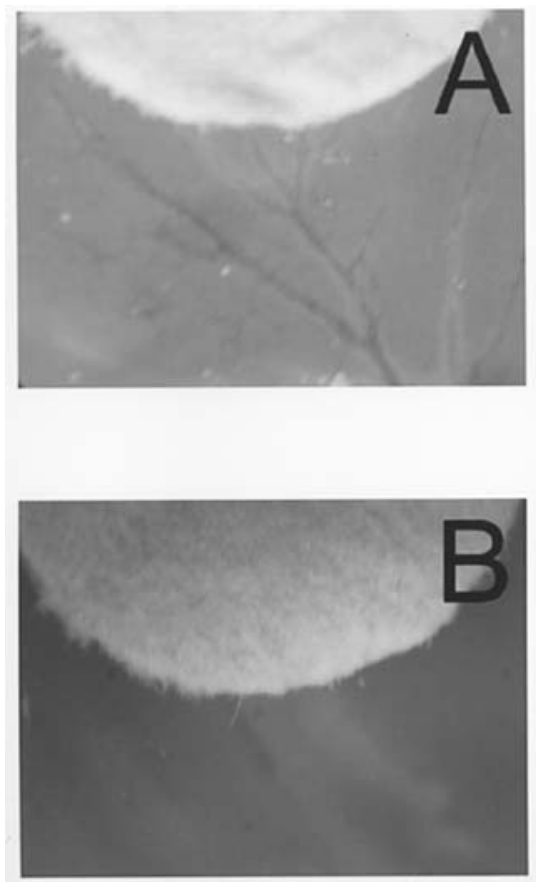

Figure 5. Chick chorioallantoic membrane assay for the effect of concentrated EM-X on the angiogenic activity of bFGF. (A) With only bFGF (40 ng). (B) With bFGF (40 ng) plus concentrated EM-X (100 $\mu \mathrm{g})$. See Materials and methods for details.

compared with 40 ng of bFGF alone. Representative micrographs are shown in Fig. 5.

\section{Discussion}

Inhibition of angiogenesis is of great importance in cancer therapy, in addition to conventional chemotherapy, since this approach is believed to be significantly less toxic on normal tissues especially in the case of adult cancer patients (9).

Recently, we demonstrated the antiproliferative effect of the concentrated EM-X on cancer cells in vitro. In order to determine whether concentrated EM-X could also be antiangiogenic, we tested it using HUCE cells as an experimental model system. Culturing HUCE cells with concentrated EM$\mathrm{X}$ at $2 \mathrm{mg} / \mathrm{ml}$ for $48 \mathrm{~h}$ caused inhibition of HUCE cell growth without activation of programmed cell death, as demonstrated morphologically, since no hallmarks of cell death, including cell shrinkage, cell detachment and cell rounding was detected under the inverted microscopic image (10). It is therefore possible that concentrated EM-X at this dose and time interval would not be toxic towards HUCE cells and might not be harmful towards vascular endothelial cells from blood vessels.

In a recent study, we showed that Hep 3B HCC cells, but not the SK-Hep1 hepatoma cells, were highly sensitive towards the concentrated EM-X at $2 \mathrm{mg} / \mathrm{ml}$ (5). Therefore, in order to understand whether concentrated EM-X could further affect the level of an important angiogenic factor, VEGF, we treated the Hep 3B HCC cells with concentrated EM-X for different doses and analyzed the VEGF level from the culture media at different intervals. After quantitating the VEGF level with ELISA assay and normalizing with the total cellular protein, 
we observed that concentrated EM-X at $2 \mathrm{mg} / \mathrm{ml}$ was effective in reducing the level of VEGF from Hep 3B HCC cells after both 24 and $48 \mathrm{~h}$. Thus, we believe that concentrated EM-X is able to directly act on the Hep 3B HCC cells to induce apoptosis and simultaneously reduce VEGF levels.

The observation of the action of concentrated EM-X on VEGF is of interest, since it is known that VEGF is an important inducer for the proliferation of HUCE cells (11). Once VEGF binds to its receptor on HUCE cells, intracellular phosphorylation is stimulated and this in turn stimulates Akt. Therefore, we verified whether the conditioned medium from concentrated EM-X-treated Hep 3B cells could further inhibit HUCE cell growth. As expected, a strong growth inhibition was found (Fig. 3B). When compared with the culturing condition from the conditioned medium from untreated Hep $3 \mathrm{~B}$ cells, the percentage of survival of HUCE cells further reduced to a mean value of $\sim 40 \%$ only. Thus, we speculated that under the in vitro condition, concentrated $\mathrm{EM}-\mathrm{X}$ at $2 \mathrm{mg} / \mathrm{ml}$ after $48 \mathrm{~h}$ could significantly inhibit the growth of Hep 3B HCC and HUCE cells while the reduced level of VEGF from the concentrated EM-X-treated HCC cells could further slow down the proliferation of HUCE cells. If this hypothesized in vitro model is achieved in vivo, concentrated EM-X might be an effective antiangiogenic regimen directly cytotoxic towards cancer cells, limiting the blood supply for tumour growth, development and metastasis.

To examine the possible antiangiogenic activity of concentrated EM-X in vivo, a chick chorioallantoic membrane assay (CAM) was preformed. The formation of new blood vessels on the chorioallantoic membrane induced from the chick embryo using bFGF was reduced when mixing with concentrated EM-X. This experimental result further provides evidence to support the possible antiangiogenic potential of concentrated EM-X in vivo. Nevertheless, athymic nude mouse xenograft model would be the next step to clarify this issue.

Many naturally occurring products are found to be both growth inhibitory and cytotoxic towards cancer cells and simultaneously possess growth inhibition towards vascular endothelial cells. One well recognized example is green tea. Green tea catechins inhibit angiogenesis by affecting the VEGF-2 mediated casacde including the vascular endothelial cadherin and Akt in the HUCE cell (12). Green tea could suppress the VE-cadherin tyrosine phosphorylation and inhibit the Akt activation during VEGF-induced tube formation (13). As we know, many traditional Chinese medicine extracts and microbial fermentation products also have anti-cancer property (14). Future experimental work on screening and the understanding of mechanisms could strengthen our knowledge to explore new drugs for cancer therapy.

\section{Acknowledgements}

We acknowledge the support by the Area of Strategic Development (ASD) programme of the Hong Kong Polytechnic University (H.K.P.U.) (work programme A012). This study was supported by the Areas of Excellence Scheme established under the University Grants Committee of the Hong Kong Special Administrative Region, China (Project No. AoE/P-10/01) and a Niche Area Grant offered by the H.K.P.U. Drs F.Y. Lau and C.H. Chui are the honourary tutors kindly offered by Professors J.J.Y. Sung and G.Y.M. Cheng from Department of Medicine and Therapeutics, Prince of Wales Hospital, The Chinese University of Hong Kong. Dr C.H. Chui would like to thank Professor A.S.C. Chan who provided a valuable opportunity to Dr C.H. Chui to be the 'Research Fellow' in the Department of Applied Biology and Chemical Technology, H.K.P.U.

\section{References}

1. Gourley M and Williamson JS: Angiogenesis: new targets for the development of anticancer chemotherapies. Curr Pharm Des 6: 417-439, 2000

2. Thorpe PE, Chaplin DJ and Blakey DC: The First International Conference on vascular targeting: meeting overview. Cancer Res 63: 1144-1147, 2003

3. Carmeliet P and Jain RK: Angiogenesis in cancer and other disease. Nature 407: 249-257, 2000.

4. Chui CH, Cheng GYM, Ke B, Lau FY, Wong RSM, Kok SHL, Fatima S, Cheung F, Cheng $\mathrm{CH}$, Chan ASC and Tang JCO: Growth inhibitory potential of effective microorganism fermentation extract (EM-X) on cancer cells. Int J Mol Med 14: 925-929, 2004.

5. Chui CH, Hau DKP, Lau FY, Cheng GYM, Wong RSM, Gambaria R, Kok SHL, Lai KB, Tang JCO, Leung TWT, Higa T, Ke B, Tang JCO, Fong DWF and Chan ASC: Apoptotic potential of concentrated effective microorganism fermentation extract on human cancer cells. Int J Mol Med 17: 279-284, 2006.

6. Chui CH, Lau FY, Tang JCO, Kan KL, Cheng GYM, Wong RSM, Kok SHL, Lai PBS, Ho R, Gambari R and Chan ACS: Activities of fresh juice of Scutellaria barbata and warmed water extract of Radix Sophorae Tonkinensis on anti-proliferation and apoptosis of human cancer cell lines. Int J Mol Med 16: 337-341, 2005.

7. Lau FY, Chui CH, Gambari R, Kok SHL, Kan KL, Cheng GYM, Wong RSM, Teo ITN, Cheng CH, Wan TSK, Chan ASC and Tang JCO: Antiproliferative and apoptosis-inducing activity of Bruces javanica extract on human carcinoma cells. Int J Mol Med 16: 1157-1162, 2005.

8. Chow LMC, Chui CH, Tang JCO, Lau FY, Yau MYC, Cheng GYM, Wong RSM, Lai PBS, Leung TWT, Teo ITN, Cheung F, Guo D and Chan ASC: Anti-angiogenic potential of Gleditsia sinensis fruit extract. Int J Mol Med 12: 269-273, 2003.

9. Folkman J: Looking for a good endothelial address. Cancer Cell 1: 113-115, 2002

10. Chui CH, Gambari R, Lau FY, Cheng GYM, Wong RSM, Kok SHL, Tang JCO, Teo ITN, Cheung F, Cheng CH, Ho KP, Chan ASC and Wong A: In vitro anti-cancer activity of a novel microbial fermentation product on human carcinoma. Int $\mathrm{J}$ Mol Med 17: 675-679, 2006.

11. Senger DR, Van de Water L, Brown LF, Nagy JA, Yeo KT, Yeo TK, Berse B, Jackman RW, Dvorak AM and Dvorak HF: Vascular permeability factor (VPF, VEGF) in tumor biology. Cancer Metastasis Rev 12: 303-324, 1993

12. Farabegoli F: Green tea in human cancer. Minerva Biotec 17: 163-173, 2005.

13. Tang FY, Nguyen $\mathrm{N}$ and Meydani M: Green tea catechins inhibit VEGF-induced angiogenesis in vitro through suppression of VE-cadherin phosphorylation and inactivation of $\mathrm{Akt}$ molecule. Int J Cancer 106: 871-878, 2003.

14. Chui CH, Gambari R, Lau FY, Teo ITN, Ho KP, Cheng GYM, Ke B, Higa T, Kok SHL, Chan ASC and Tang JCO: Anti-cancer potential of traditional Chinese herbal medicines and microbial fermentation products. Minerva Biotec 17: 183-191, 2005. 